\title{
Placental growth factor-1 and epithelial haemato-retinal barrier breakdown: potential implication in the pathogenesis of diabetic retinopathy
}

\author{
N. Miyamoto • Y. de Kozak • J. C. Jeanny • A. Glotin • \\ F. Mascarelli • P. Massin • D. BenEzra • F. Behar-Cohen
}

Received: 29 July 2006 / Accepted: 10 October 2006 / Published online: 23 December 2006

(C) Springer-Verlag 2006

\begin{abstract}
Aims/hypothesis Disruption of the retinal pigment epithelial (RPE) barrier contributes to sub-retinal fluid and retinal oedema as observed in diabetic retinopathy. High placental growth factor (PLGF) vitreous levels have been found in diabetic patients. This work aimed to elucidate the influence of PLGF-1 on a human RPE cell line (ARPE19) barrier in vitro and on normal rat eyes in vivo.

Methods ARPE-19 permeability was measured using transepithelial resistance and inulin flux under stimulation of PLGF-1, vascular endothelial growth factor (VEGF)-E and VEGF165. Using RT-PCR, we evaluated the effect of
\end{abstract}

This work was presented in part at the Association for Research and Vision in Ophthalmology meeting, Fort Lauderdale, FL, USA, in May 2005.

N. Miyamoto $\cdot$ Y. de Kozak · J. C. Jeanny · A. Glotin •

F. Mascarelli $\cdot$ F. Behar-Cohen $(\bowtie)$

INSERM U598, Physiopathology of Ocular Diseases:

Therapeutic Innovations, Biomedical Institute des Cordeliers,

15 rue de l'Ecole de médecine,

75006 Paris, France

e-mail: behar@idf.inserm.fr

N. Miyamoto $\cdot$ Y. de Kozak $\cdot$ J. C. Jeanny $\cdot$ A. Glotin $\cdot$

F. Mascarelli $\cdot$ F. Behar-Cohen

René Descartes University,

Paris, France

P. Massin

Department of Ophthalmology, Lariboisière Hospital,

Paris, France

D. BenEzra

Hadassah Hebrew University Hospital,

Jerusalem, Israel

F. Behar-Cohen

Rothschild Foundation, Laboratory of Therapeutic Innovation,

Paris, France hypoxic conditions or insulin on transepithelial resistance and on PLGF-1 and VEGF receptors. The involvement of mitogen-activated protein kinase kinase (MEK)/extracellular signal-regulated kinase (ERK, also known as EPHB2) signalling pathways under PLGF-1 stimulation was evaluated by western blot analysis and specific inhibitors. The effect of PLGF-1 on the external haemato-retinal barrier was evaluated after intravitreous injection of PLGF-1 in the rat eye; evaluation was by semi-thin analysis and zonula occludens-1 immunolocalisation on flat-mounted RPE.

Results In vitro, PLGF-1 induced a reversible decrease of transepithelial resistance and enhanced tritiated inulin flux. These effects were specifically abolished by an antisense oligonucleotide directed at VEGF receptor 1. Exposure of ARPE-19 cells to hypoxic conditions or to insulin induced an upregulation of PLGF-1 expression along with increased transcellular permeability. The PLGF-1-induced RPE cell permeability involved the MEK signalling pathway. Injection of PLGF-1 into the rat eye vitreous induced an opening of the RPE tight junctions with subsequent sub-retinal fluid accumulation, retinal oedema and cytoplasmic translocation of junction proteins.

Conclusions/interpretation Our results indicate that PLGF1 may be a potential regulation target for the control of diabetic retinal and macular oedema.

Keywords Diabetes · Haemato-retinal barrier . Junction proteins $\cdot$ Macula $\cdot$ Oedema $\cdot$ PLGF-1 $\cdot$ Retina . VEGF receptors
Abbreviations
ARPE- a human RPE cell line
19
ERK extracellular signal-regulated kinase 


$\begin{array}{ll}\text { MEK } & \text { mitogen-activated protein kinase kinase } \\ \text { MTT } & \begin{array}{l}\text { 3-(4,5-dimethylthiazol-2-yl)-2,5-diphenyltetra- } \\ \text { zolium bromide] }\end{array} \\ \text { PLGF } & \begin{array}{l}\text { placental growth factor } \\ \text { retinal pigment epithelial }\end{array} \\ \text { RPE } & \text { transepithelial electrical resistance } \\ \text { TER } & \text { vascular endothelial growth factor } \\ \text { VEGF } & \text { vascular endothelial growth factor receptor } \\ \text { VEGFR } & \text { zonula occludens-1 }\end{array}$

\section{Introduction}

Ocular neovascularisation (angiogenesis) and macular oedema are frequent complications of diabetic retinopathy leading to loss of vision. Cytokines, chemokines and most notably vascular endothelial growth factor (VEGF) contribute to ocular angiogenesis and vascular permeability [1-4]. The effect of VEGF on the blood-brain and bloodretinal barriers has been studied extensively. It was found that the vascular barrier breakdown is associated with increased vesicular transport and decreased tight junction protein content of vascular endothelial cells $[5,6]$. These phenomena are apparently mediated by VEGF receptor (VEGFR)-2 and VEGFR-1 [7, 8]. In the retina, vascular endothelial cells, pericytes, glial and retinal pigment epithelial (RPE) cells produce VEGF and also produce its receptors $[1,9]$.

Apart from the internal retinal-blood barrier, another 'external' retinal-blood barrier provides a selectively permeable barrier between the choroid and the neurosensory retina and actively maintains the neuroretina attached. This second barrier is controlled by RPE cells and their tight junctions. The fluid balance within the retina depends on a healthy and functional RPE cell layer.

Beside VEGF, human RPE cells under hypoxia produce another member of the VEGF superfamily, the placental growth factor (PLGF) [9]. Interestingly, high PLGF-1 levels have been found in the vitreous of patients with diabetic retinopathy [10]. However, the exact role of PLGF in ocular tissues remains unclear. PLGF is a homodimeric protein that shares substantial structural similarity with VEGF-A. Three PLGF isoforms have been described (PLGF-1, -2 and -3). These isoforms do not interact with VEGFR-2 but do bind to VEGFR-1 [11].

VEGF- and PLGF-induced vascular permeability has been studied extensively. PLGF and its receptor are also implicated in inflammatory processes occurring in atherosclerosis and rheumatoid arthritis [12] and participate in the angiogenic activity of non-endothelial cells [13]. However, the potential influence of PLGF-1 on RPE barrier regulation has not been thoroughly investigated.
In this study, using cultures from the human RPE cell line, ARPE-19, we investigated the potential role of PLGF-1 and specific VEGF receptors in permeability of the RPE blood-retinal barrier under normal and hypoxic conditions. Transduction pathways involved in VEGFR-1-mediated permeability were also studied. Since macular oedema is more frequently observed in the hyperinsulinaemic type 2 diabetes [14] and insulin treatment is associated with early aggravation of diabetic retinopathy, we also evaluated the effect of insulin on PLGF-1 production and RPE barrier integrity. The effect of PLGF-1 on the external retinalblood barrier was also studied in vivo in the rat eye.

\section{Materials and methods}

Human RPE cell culture A spontaneously immortalised human RPE cell line (ARPE-19 [ATCC CRL-2302]) [15] was cultured in a mixture of 1:1 DMEM and Nutrient Mixture F12, with HEPES buffer (Gibco, Grand Island, NY, USA) supplemented with $10 \%$ fetal bovine serum. ARPE-19 cells were seeded at a density of $1.5 \times 10^{5}$ cells $/ \mathrm{cm}^{2}$ in either $25-\mathrm{cm}^{2}$ flasks (Becton Dickinson, Le pont de Claix, France) or on polyester filters (Transwell, $0.4 \mu \mathrm{m}$ pore size, $6.5 \mathrm{~mm}$ in diameter; Costar, Cambridge, MA, USA). The cultures were kept at $37^{\circ} \mathrm{C}$ in a $5 \% \mathrm{CO}_{2}$ humidified atmosphere.

Treatment of ARPE-19 cell cultures ARPE-19 cell cultures were exposed to either VEGF-165 (1 nmol/l), PLGF-1 ( $2 \mathrm{nmol} / 1$ and $0.2 \mathrm{nmol} / \mathrm{l}$; agonist for VEGFR-1) or VEGFE (1 nmol/l; agonist for VEGFR-2) (Relia Tech, Brunswick, Germany) in serum-free medium for various periods of time. To study whether the extracellular signal-regulated kinase (ERK, also known as EPHB2) pathway is involved, ARPE-19 cells were starved of serum for $48 \mathrm{~h}$ before the experiment and the mitogen-activated protein kinase kinase (MEK) 1/2 inhibitor, UO126 (10 $\mu \mathrm{mol} / 1$; Calbiochem, San Diego, CA, USA) was added $1 \mathrm{~h}$ prior to the addition of PLGF-1. To mimic hypoxic conditions, ARPE-19 cell monolayers were incubated with $\mathrm{CoCl}_{2}(10 \mu \mathrm{mol} / \mathrm{l})$ (Sigma Aldrich, Saint-Quentin Fallavier, France) as previously described [16]. The viability of ARPE-19 cells after exposure to hypoxic conditions for variable periods of time was evaluated using a 3-(4,5-dimethylthiazol-2-yl)-2,5diphenyltetrazolium bromide (MTT) assay. Briefly, after $1 \mathrm{~h}$ incubation in MTT $(250 \mu \mathrm{l}$ per well in 24-well plates) at $37^{\circ} \mathrm{C}$, the resulting insoluble formazan crystals are dissolved in $250 \mu \mathrm{l}$ of isopropanol and absorbance spectroscopy measured at 540 and $630 \mathrm{~nm}$ using an adapted plate spectrophotometer. Using a standard curve for each experiment, the colour intensity observed in each well is correlated to the number of viable cells. To evaluate the 
effect of insulin on PLGF-1 production and ARPE-19 cell permeability, cells were exposed to insulin (100 nmol/l) (Sigma Aldrich) for various periods up to $48 \mathrm{~h}$.

Transepithelial electrical resistance measurements Transepithelial electrical resistance (TER) across the monolayers was monitored every week until the fourth week of culture using a resistance system (Millicell; Millipore, Bedford, MA, USA) connected to dual Ag-AgCl electrodes. Net TER values were calculated by subtracting the mean resistance determined for ten plastic filters in the absence of cells from the values recorded for each cell monolayer grown on similar filters. Resistance was expressed in $\Omega \times \mathrm{cm}^{2}$. After TER stabilisation (3 to 4 weeks of culture), ARPE-19 cells were treated with different stimulants and changes in TER were monitored after $1,6,24,48$ and $72 \mathrm{~h}$ of incubation. $\triangle \mathrm{TER}$ corresponds to the difference between TER values of ARPE-19 cell monolayers before (control cells) and after stimulation. Values are illustrated as the mean results of five independent cultures.

Permeability assay by $\left[{ }^{3} H\right]$ inulin flux In order to determine whether TER changes were related in part to paracellular increased permeability of cultured RPE cells, we measured the passive permeation of $\left[{ }^{3} \mathrm{H}\right]$ inulin across confluent cells grown on filters. The apical and basal sides of the cell layers were bathed in $200 \mu \mathrm{l}$ and $800 \mu \mathrm{l}$ serum-free culture medium, respectively, containing the different stimulants and supplemented with $1 \mathrm{mmol} / \mathrm{l}$ unlabelled inulin (Sigma Aldrich). These incubation volumes were chosen to avoid interference from hydrostatic pressure. Radioactive $\left[{ }^{3} \mathrm{H}\right]$ inulin $(2 \mu \mathrm{Ci}$; specific activity, $1.95 \mathrm{mCi} / \mathrm{mmol})$ was added to the medium bathing the apical side of the cells. Aliquots of $50 \mu \mathrm{l}$ were collected from the lower chambers at different time points during $72 \mathrm{~h}$. The radioactivity $\left({ }^{3} \mathrm{H}\right)$ in the collected aliquots was counted in a liquid scintillation analyser (Packard, Meriden, CT, USA). All measurements were performed in triplicate and illustrated as the mean dpm of test culture.

Evaluation of PLGF-1, VEGFR-1 and VEGFR-2 by semiquantitative RT-PCR The influence of hypoxia on PLGF-1, VEGFR-1 and VEGFR-2 production was evaluated using RT-PCR analysis in normal and hypoxic conditions. Cells were grown on $25-\mathrm{cm}^{2}$ flasks and total RNA was prepared using a kit (RNAeasy Mini; Qiagen, Les Ulis, France). First-strand cDNA was generated by reverse transcription of 100 ng total RNA using oligo dT (Invitrogen, Cergy Pontoise, France) with Moloney Murine Leukaemia Virus reverse transcriptase according to the instructions of the suppliers (Invitrogen). This process yielded $20 \mu \mathrm{l}$ cDNA of which $1 \mu \mathrm{l}$ was used for each semi-quantitative PCR analysis.
The cDNAs were amplified in a $50-\mu \mathrm{l}$ reaction volume containing $20 \mathrm{mmol} / 1$ Tris- $\mathrm{HCl}(\mathrm{pH} 8.4), 50 \mathrm{mmol} / 1$ potassium chloride, $1.5 \mathrm{mmol} / 1$ magnesium chloride, $0.2 \mathrm{mmol} / 1$ of each of the dNTPs and $0.5 \mu \mathrm{mol} / 1$ of each appropriate primer: GGCGATGAGAATCTGCACTGT-3' (forward), 5'-CA CCTTTCCGGCTTCATCTTC-3' (reverse) for PLGF [17]; 5'-CAAGTGGCCAGAGGCATGGAGTT-3' (forward), 5'GATGTAGTCTTTACCATCCTGTTG-3' (reverse) for VEGFR-1 [18]; 5'-GAGGGCCTCTCATGGTGATTGT-3' (forward), 5'-TGCCAGCAGTCCAGCATGGTCTG-3' (reverse) for VEGFR-2 [18]; and 5'-AGGAGAAGCTTGC TACGTC-3' (forward), 5'-AGGGGCCGGACTCGTCATAC-3' (reverse) for $\beta$-actin, and $2 \mathrm{U}$ Taq polymerase (Invitrogen).

PCR in exponential phase consisted of 1 cycle of denaturation at $95^{\circ} \mathrm{C}$ for $30 \mathrm{~s}$, annealing at $55^{\circ} \mathrm{C}(\beta$-actin), $57^{\circ} \mathrm{C}$ (PLGF, VEGFR-1 and -2) for $30 \mathrm{~s}$ and extension at $72^{\circ} \mathrm{C}$ for $60 \mathrm{~s}$, followed by 35 cycles for PLGF, VEGFR-1 and VEGFR-2, and 25 cycles for $\beta$-actin. Each PCR reaction was performed in triplicate. Experiments were reproduced three times. PLGF, VEGFR-1, VEGFR-2 and $\beta$-actin PCR products were separated on $1.5 \%$ agarose gels using ethidium bromide for visualisation and yielded the expected amplicon sizes of 164, 498, 706 and 465 bp, respectively. Band intensity was quantified using the $\mathrm{NIH}$ 1.57 software package (NIH, Bethesda, MD, USA). Expression levels of the gene encoding $\beta$-actin (also known as $A c t b)$ were used for standardisation. Results were expressed as the ratio of specific gene: $\beta$-actin expression.

Downregulation of VEGFR-1 and VEGFR-2 as determined by antisense oligonucleotides In order to demonstrate the specificity of VEGF receptors in mediating RPE cell permeability, we have designed specific antisense oligonucleotides directed at VEGFR-1 and VEGFR-2.

A preliminary experiment was performed to confirm the specificity and efficacy of these antisense oligonucleotides. Cells were seeded on $25-\mathrm{cm}^{2}$ flasks for 7 days and then treated with specific antisense or scrambled oligonucleotides. The following phosphorothioate oligonucleotides were used: VEGFR-1 antisense: 5'-GTAGCTGACCATGG TGAGCG-3'; VEGFR-1 scrambled: 5'-ATCAGC GTGTGAGCACGGTG-3'; VEGFR-2 antisense: 5'GCATCTCCTTTTCTGAC-3'; and VEGFR-2 scrambled: 5'-TTAATCGTTCTCTGCCC-3'.

Oligonucleotides $(8.0 \mu \mathrm{g}, 1 \mu \mathrm{mol} / \mathrm{l})$ and $20 \mu \mathrm{l}$ of Lipofectamine 2000 reagent (Invitrogen, Carlsbad, CA, USA) were diluted separately each in $500 \mu \mathrm{l}$ of Opti-MEM Reduced Serum Medium and incubated at room temperature for $5 \mathrm{~min}$. This mixture was added to each flask containing $2.0 \mathrm{ml}$ Opti-MEM and incubated at $37^{\circ} \mathrm{C}$ for $5 \mathrm{~h}$. The transfection culture medium was then gently removed and replaced with DMEM containing 10\% fetal bovine serum. The cells were collected after $24 \mathrm{~h}$ for western blotting. 
Antisense oligonucleotides were then used to pretreat confluent ARPE-19 monolayers before TER measurements under stimulation by VEGF165 as described above.

Western blot analysis In order to identify the potential implication of ERK1/2 signalling pathways in PLGF-1mediated permeability, the phosphorylation of ERK1/2 under PLGF-1 stimulation was evaluated using western blot analysis. ARPE-19 cells were washed three times in PBS, lysed in ice-cold lysis buffer $(50 \mathrm{mmol} / \mathrm{l}$ Tris- $\mathrm{HCl}$, pH 7.5, $100 \mathrm{mmol} / \mathrm{l} \mathrm{NaCl}, 0.1 \%$ Nonidet P-40, $1 \%$ deoxycholate, $50 \mathrm{mmol} / 1 \beta$-glycerophosphate, $0.2 \mathrm{mmol} /$ 1 sodium orthovanadate, $50 \mathrm{mmol} / \mathrm{l}$ sodium fluoride, $1 \mu \mathrm{g} /$ $\mathrm{ml}$ leupeptin, $5 \mu \mathrm{mol} / 1$ pepstatin, 20 trypsin inhibitor units/ $\mathrm{ml}$ aprotinin, $1 \mathrm{mmol} / 1$ phenylmethylsulfonyl fluoride), and centrifuged at $4^{\circ} \mathrm{C}$ for $10 \mathrm{~min}$ at $10,000 \mathrm{~g}$. Protein concentrations were determined with a protein assay reagent (Bio-Rad, Hercules, CA, USA) according to the Bradford method. Cell lysates were mixed with $3 \times$ Laemmli buffer and heated for $5 \mathrm{~min}$ at $95^{\circ} \mathrm{C}$. They were then resolved by SDS-PAGE (4-12\% polyacrylamide gel), transferred onto polyvinylidene difluoride membranes (Immobilon 228; Millipore, Herts, UK), and probed with polyclonal antibodies directed against VEGFR-1 (dilution 1:200; Santa Cruz Biotechnology, Santa Cruz, CA, USA), VEGFR-2 (dilution 1:200; Santa Cruz Biotechnology), phospho-ERK1/2 (Thr-202/Tyr-204) (dilution 1:1,000; Cell Signaling, Arundel, Australia), or ERK1/2 (dilution 1:1,000; Cell Signaling). Horseradish peroxidase-conjugated anti-rabbit antibodies were used as secondary antibodies and visualisation carried out by electrochemoluminescence (Amersham, Orsay, France).

Effect of PLGF-1 and VEGF-E on RPE cell junctions and retinal structure in rat eyes To study the effect of PLGF-1 on RPE cells junctions in vivo, female Lewis rats, 6 to 7 weeks old and weighing 150 to $200 \mathrm{~g}$ (IFFA CREDO, Lyon, France) were used. Experiments were conducted in accordance with the ARVO Statement for the Use of Animals in Ophthalmic and Vision Research. Rats were held for 1 week before experimentation.

Rats were anaesthetised by intraperitoneal pentobarbital injection $(40 \mathrm{mg} / \mathrm{kg})$. They received a single intravitreous injection of $5 \mu \mathrm{l}$ containing either $2 \mathrm{nmol} / \mathrm{l}$ PLGF-1 or VEGF-E diluted in PBS or an injection of $5 \mu \mathrm{l}$ PBS alone ( $n=8$ eyes per treatment and per time point). The amount of PLGF-1 injected in vivo in this acute model in the rat was calculated in order to obtain $0.2 \mathrm{nmol} / 1(3.8 \mathrm{ng} / \mathrm{ml})$ final concentration in the rat vitreous. Four additional rats $(n=4$ eyes) did not receive any injection and were used as controls for the injection procedure,

At $6 \mathrm{~h}, 24 \mathrm{~h}$ and 4 days after injection, rats were killed by an overdose of pentobarbital. Half of the treated rats in each group were used for immunolocalisation of the tightjunction associated protein zonula occludens-1 (ZO-1) on $\mathrm{RPE} /$ choroid flat mounts; the other half were used for analysis of the retinal structure using semi-thin sections.

For immunohistochemistry, eyes were enucleated and fixed in $2 \%$ paraformaldehyde for $1 \mathrm{~h}$. Biomicroscopic dissection of the sclera, choroid and RPE complex was achieved after removal of the cornea and extirpation of the lens, vitreous body and retina. The sclera, choroid and RPE complex were washed three times for $5 \mathrm{~min}$ in $1 \% \mathrm{BSA} /$ PBS, then washed three times for $10 \mathrm{~min}$ in $1 \%$ BSA/PBS and $0.2 \%$ saponin, and subsequently incubated overnight at $4^{\circ} \mathrm{C}$ with rat anti-ZO- 1 antibody $(1: 200$; Chemicon, Temecula, CA, USA) diluted in $1 \%$ BSA/PBS and $0.2 \%$ saponin. ZO-1 was visualised by incubation with Alexaconjugated goat anti-rat IgG (1:100; Molecular Probes, Eugene, OR, USA). The complex was finally mounted using glycerol/PBS (vol/vol) and observed with appropriate filters using a confocal microscope (LSM 510; Zeiss, Zurich, Switzerland).

For histology, the eyes were enucleated and fixed in $2.5 \%$ glutaraldehyde in cacodylate buffer $(\mathrm{Na} 0.1 \mathrm{~mol} / \mathrm{l}$, $\mathrm{pH}$ 7.4). After $1 \mathrm{~h}$, the globes were dissected at the limbus, the posterior eyeball post-fixed for $3 \mathrm{~h}$. Tissues were postfixed in $1 \%$ osmium tetroxide in cacodylate buffer $(\mathrm{Na}$ $0.1 \mathrm{~mol} / \mathrm{l}, \mathrm{pH}$ 7.4) and dehydrated in graduated ethanol solution $(50,70,95,100 \%)$. The tissues were then included in epoxy resin and oriented. Semi-thin sections $(1 \mu \mathrm{m})$, obtained with an ultramicrotome cutting device (Reichert Ultracut E; Leica, Rueil Malmaison, France), were stained by toluidine blue. Sections were examined with a light microscope. For all eyes, the retinal thickness was measured at a distance of $400 \mu \mathrm{m}$ from each edge of the optic nerve for the length of $400 \mu \mathrm{m}(n=10$ values for each eye). Results were expressed as the mean \pm SD.

Concentration of PLGF in human vitreous as determined by ELISA To confirm the potential implication of PLGF-1 in the pathogenesis of diabetic retinopathy, samples of vitreous from patients with diabetic retinopathy (type 2 diabetes; $n=7$ ) or with epiretinal membranes (control; $n=6$ ) were collected after Institutional Review Board approval and provision of informed consent by patients. Undiluted samples of vitreous from patients undergoing programmed vitrectomy were collected and frozen at $-20^{\circ} \mathrm{C}$ prior to testing. PLGF was measured using a sandwich ELISA (Quantikine ELISA kit; R\&D Systems, Abingdon, UK) according to the manufacturer's instructions. The minimal dose detection threshold for the assay was $7.0 \mathrm{pg} / \mathrm{ml}$.

Statistical analysis For two-group comparisons, statistical analysis was performed using the Mann-Whitney $U$ test 
( $p<0.05$ was considered significant). For multiple-group analysis, statistical analysis was performed using an ANOVA test followed by a multiple comparison Bonferroni post-test ( $p<0.05$ was considered significant).

\section{Results}

Activation of VEGFR-1 by PLGF-1 or VEGF influences paracellular permeability of human RPE cells in vitro After 4 weeks of culture, ARPE-19 cells formed confluent monolayers with a constant mean TER level of $60 \pm$ $8.6 \Omega \times \mathrm{cm}^{2}$. A preliminary dose-response effect of PLGF was observed on both TER and inulin flux when 0.2 and $2.0 \mathrm{nmol} / 1 \mathrm{PLGF}-1$ were used. The $0.2 \mathrm{nmol} / 1$ dose induced a lower effect. For further analysis, the higher PLGF doses were used. Incubation of RPE cells with $1.0 \mathrm{nmol} / \mathrm{l}$ VEGF165 or $2.0 \mathrm{nmol} / \mathrm{l} \mathrm{PLGF}-1$, which interacts exclusively with VEGFR-1

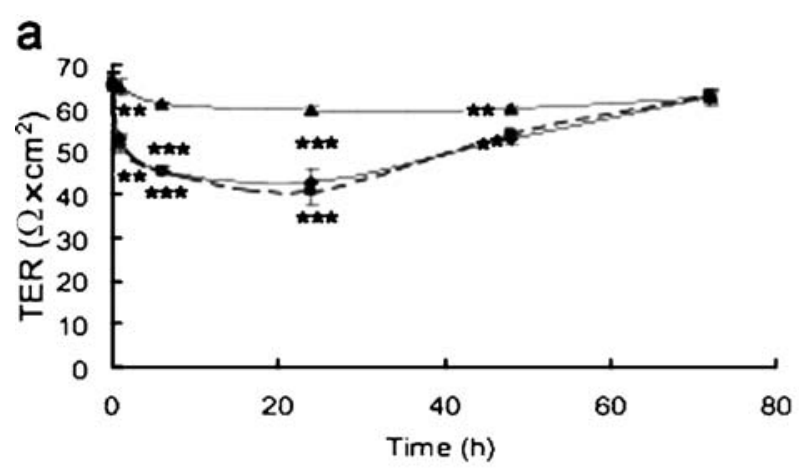

C

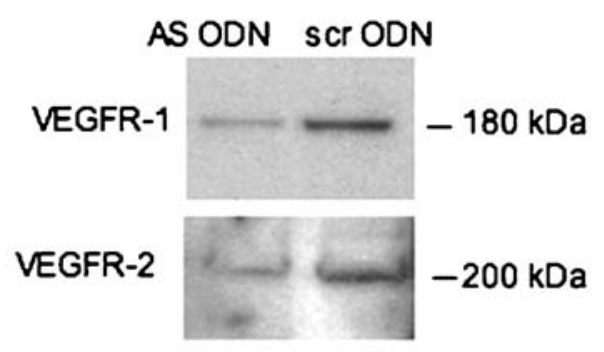

Fig. 1 Effects of VEGF165, PLGF-1, VEGF-E, and VEGFR-1 or VEGFR-2 antisense oligonucleotides on ARPE-19 cell permeability. Paracellular permeability was assessed by TER or by apical to basal $\left[{ }^{3} \mathrm{H}\right]$ inulin flux measurements on ARPE-19 monolayers. a Time course of net TER (mean $\pm \mathrm{SD}, n=3$ ) decrease after incubation with $1.0 \mathrm{nmol} / 1$ VEGF165 (filled squares), $2.0 \mathrm{nmol} / 1$ PLGF-1 (black rhombus) and $1.0 \mathrm{nmol} / 1 \mathrm{VEGF}-\mathrm{E}$ (grey triangles). $* * p<0.01 ; * * * p$ $<0.001$. Net TER corresponds to the difference between TER values of cell monolayer and of filter TER. b Time course of inulin flux across ARPE-19 monolayers after incubation with $1.0 \mathrm{nmol} / 1$ VEGF165 (grey bars), $2.0 \mathrm{nmol} / 1$ PLGF-1 (filled bars) and $1.0 \mathrm{nmol} / 1$ VEGF-E (hatched
[11], induced a rapid significant decrease in TER $(p<0.01)$. The decrease remained highly significant at 6 and $24 \mathrm{~h}(p<$ 0.001 ), with a slow recovery observed at $72 \mathrm{~h}$ (Fig. 1a). The TER decrease correlated well with the inulin flux, which was significantly increased at 1,6 and $24 \mathrm{~h}$ after addition of VEGF165 or PLGF-1 $(p<0.01)$ (Fig. 1b). Incubation with $1.0 \mathrm{nmol} / 1$ VEGF-E, a specific agonist of VEGFR-2, affected neither TER (Fig. 1a) nor inulin flux ( $p>0.05$ for both). To confirm that RPE permeability was specifically dependent on VEGFR-1, we used antisense oligonucleotides to specifically downregulate VEGFR-1 or VEGFR-2 expression. Western blot analysis confirmed that antisense oligonucleotides specifically downregulated VEGFR-1 or VEGFR-2 (Fig. 1c). Pretreatment of the cells with the VEGFR-1 antisense oligonucleotide prevented the VEGF165-induced decrease in TER, whereas treatment with the VEGFR-2 antisense oligonucleotide did not affect VEGF165-induced RPE cell permeability (Fig. 1d).
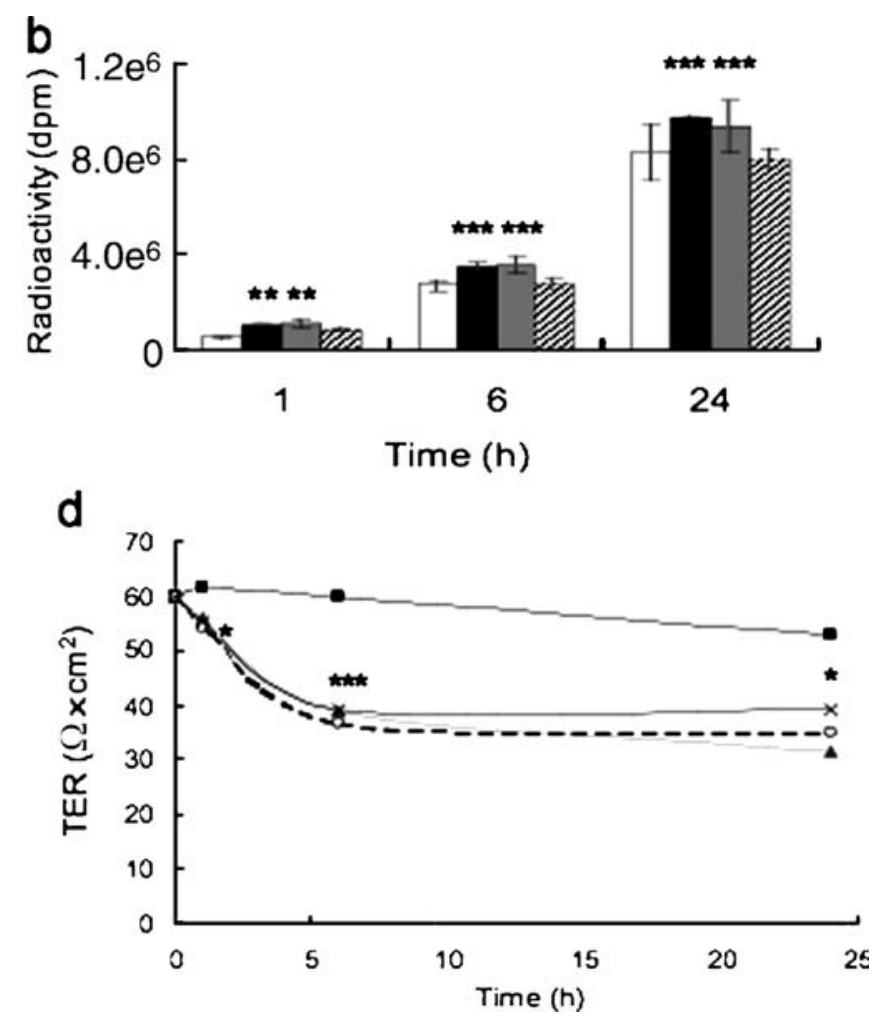

bars), control, open bars. $\left[{ }^{3} \mathrm{H}\right]$ Inulin flux was measured by counting radioactivity (dpm) in $10-\mu$ l samples over a period of 1 to $72 \mathrm{~h}(n=3)$. ${ }^{*} p<0.05 ;{ }^{*} p<0.01$. c Western blot showing the downregulation of VEGF receptors by treatment with VEGFR-1 and VEGFR-2 antisense oligonucleotides (AS ODN). Scrambled oligonucleotide (Scr ODN), used as a control, had no effect. d Specific inhibition of the VEGF165induced decrease in TER by prior treatment for $5 \mathrm{~h}$ with VEGFR-1 AS ODN. No such inhibition is observed with VEGFR-2 AS ODN $(n=3)$. Filled squares, VEGFR-1 AS; grey triangles, VEGFR-1 scr; open circles, VEGFR-2 AS; grey crosses, VEGFR-2 scr. ${ }^{*} p<0.05$, $* * * p<0.001$ 
Exposure of human RPE cells to hypoxic conditions or insulin upregulates PLGF-1 and increases permeability of RPE monolayers Because hypoxia and IGF-1 induce the production of angiogenic and permeating factors [19], we investigated the upregulation of PLGF-1 production and its influence on RPE cell permeability after exposure of RPE cells to hypoxia and insulin.

In RT-PCR analysis only very low basal levels of Plgf-1 mRNAs were detected in ARPE-19 control cultures (Fig. 2a). Sustained exposure (15 h) of ARPE-19 cells to $\mathrm{CoCl}_{2}$ (mimicking hypoxic conditions), significantly upregulated Plgf-1 mRNA expression $(p<0.05)$ (Fig. 2a). Also, low levels of Vegfr-1 and Vegfr-2 mRNAs were expressed in RPE cells under basal conditions (Fig. 2b,c). However, under hypoxic conditions Vegfr-1 mRNA expression was upregulated. A significant upregulation of $V e g f r-1$ was detected as early as $3 \mathrm{~h}$ after exposure of the cultures to hypoxic conditions and lasted for at least $15 \mathrm{~h}$ (Fig. 2b). During this period, no significant changes were observed in Vegfr-2 mRNA expression (Fig. 2c). Moreover, RPE cell permeability was significantly increased under hypoxia at $24 \mathrm{~h}$ and during a 72 -h period $(p<0.05)$ (Fig. $2 \mathrm{~d}, \mathrm{e})$. In the MTT assay no significant decrease in ARPE-19 viability was observed after either 24,48 or $72 \mathrm{~h}$ of hypoxia (not shown), demonstrating that the decrease in TER was not related to reduced cell viability.

Interestingly, exposure of RPE cells to insulin $(100 \mathrm{nmol} / \mathrm{l})$ also induced a significant and transitory upregulation of Plgf-1 mRNA expression at 6 h (Fig. 3a). This upregulation was accompanied by a significant increase in RPE cell permeability (TER: $p<0.001$; inulin flux: $p<0.05)$ at 6 and 24 h (Fig. 3b,c).

PLGF-1-induced RPE cell permeability involves the MEK/ ERK signalling pathway A recent publication shows that in human colorectal cancer cells, VEGFR-1-induced motility involves ERK1/2 activation [20].

We investigated the levels of ERK1/2 phosphorylation by western blot analysis with antibodies that specifically recognise phosphorylated active forms of ERK1/2 (Fig. 4a). Stimulation of RPE cells by PLGF-1 increased the levels of ERK1/2 phosphorylation as early as $10 \mathrm{~min}$ after exposure. However, $1 \mathrm{~h}$ after PLGF-1 stimulation, phosphorylated ERK1/2 returned to its basal levels. Pharmacological inhibition of MEK1/2, the direct upstream activator of ERK1/2, resulted in the complete inhibition of ERK1/2 a
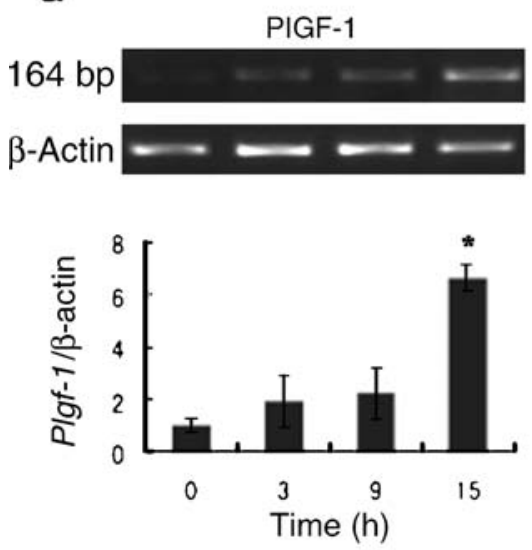

d

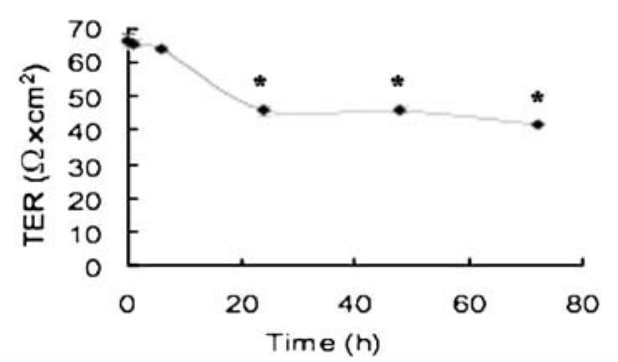

Fig. 2 Effect of hypoxia on Plgf-1, Vegfr-1 and Vegfr-2 mRNA expression and on ARPE-19 cell permeability. Time course of expression of Plgf-1 (a), Vegfr-1 (b) and Vegfr-2 mRNA (c) in RTPCR products from ARPE-19 cells under hypoxia. Agarose gel electrophoresis of the PCR products is presented and results expressed as means $\pm \mathrm{SD}$ of signal intensity relative to $\beta$-actin $(n=3) .{ }^{*} p<0.05$; ${ }^{* *} p<0.01$. d Time course of RPE cell TER decrease under hypoxia

e
VEGFR-1
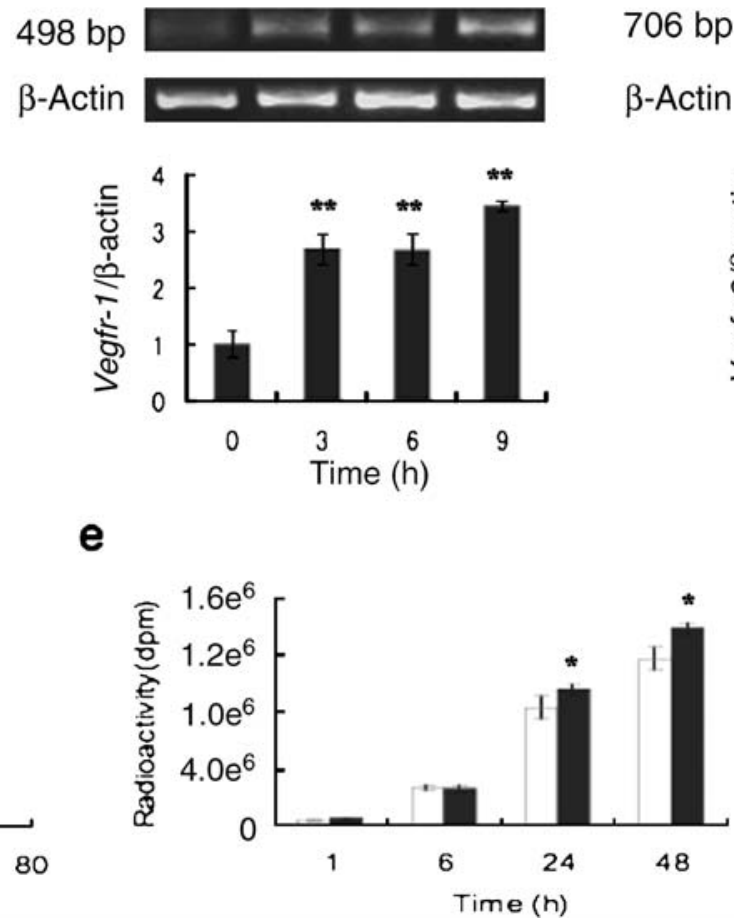

$\left(\Omega \times \mathrm{cm}^{2}\right)$. Results are expressed as net TER corresponding to the difference between TER values of cell monolayer and of filter TER (values are mean $\pm \mathrm{SD}, n=3$ ). ${ }^{*} p<0.05$. e Time course of inulin flux across RPE cells after exposure to hypoxic conditions. Apical to basal $\left[{ }^{3} \mathrm{H}\right]$ inulin flux was measured in the aliquots collected from the basal side of the filters by counting radioactivity (dpm over a period of 1 to $48 \mathrm{~h} ;(n=3)$. Open bars, control; filled bars, $\mathrm{CoCl}_{2} .{ }^{*} p<0.05$ 
Fig. 3 Effect of insulin on PLgf-1 mRNA expression and RPE cell permeability. a Time course of PLgf-1 RT-PCR products in RPE cells exposed to insulin. Results are expressed as means \pm SD of $P L g f-1: \beta$-actin ratios $(n=3) * p<0.05$. b Time course of TER measured in RPE cells exposed to insulin $\left(\Omega \times \mathrm{cm}^{2}\right)$. Results are expressed as net TER means $( \pm \mathrm{SD})$ in comparison with mean TER before exposure to insulin ( $n=$ 3). ${ }^{* * *} p<0.001$. c Time course of inulin flux across RPE cells exposed to insulin (filled bars; control: open bars). $\left[{ }^{3} \mathrm{H}\right]$ Inulin flux was measured by counting radioactivity (dpm) in $10-\mu 1$ samples over a period of 1 to $48 \mathrm{~h}(n=3) .{ }^{*} p<0.05$
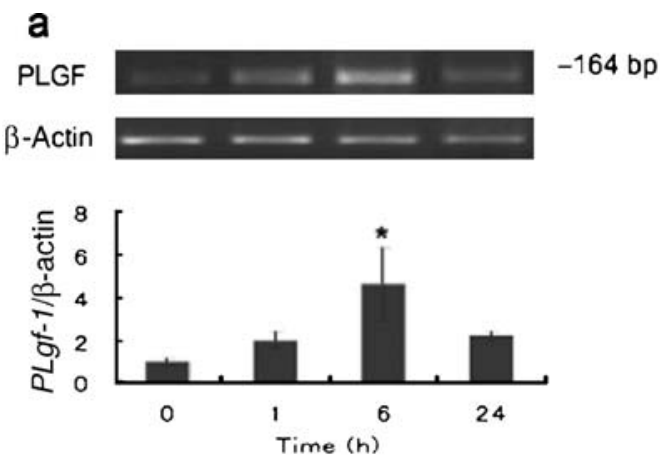

b

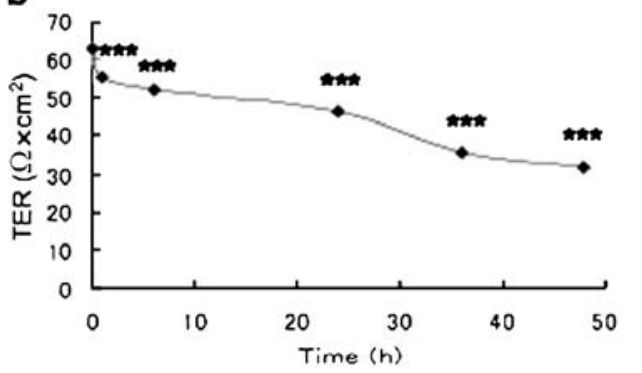

C

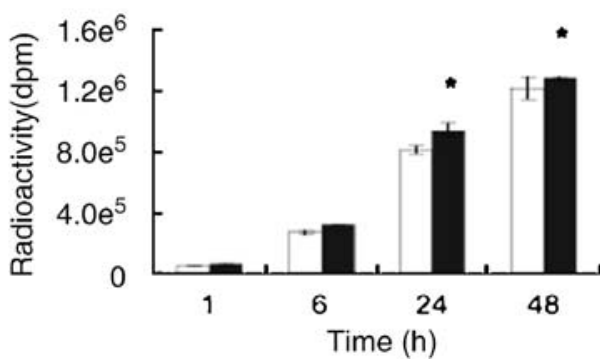

phosphorylation, whereas the expression levels of ERK1/2 did not change. To determine whether activation of the MEK/ ERK signalling pathway was involved in PLGF-induced cell permeability, cells were treated with $10 \mu \mathrm{mol} / \mathrm{l}$ of UO126, a specific inhibitor of MEK1/2. Inhibition of MEK1/2 completely abolished the effects of VEGF165 and PLGF-1 on TER (Fig. 4b) and inulin flux (Fig. 4c). These experiments demonstrate that PLGF-1-mediated activation of VEGFR-1 and the subsequent increase of RPE permeability involve the MEK/ERK signalling pathway.

PLGF-1 induces a rupture of the external blood-retinal barrier in the rat eye At $24 \mathrm{~h}$ after intravitreous injection,
RPE cells of control PBS-injected eyes had undisturbed tight junctions (Fig. 5a). In eyes injected with PLGF-1, disruption of the tight junctions was already detected $6 \mathrm{~h}$ after the injection (data not shown). At $24 \mathrm{~h}$, opening of RPE tight junctions and ZO-1 redistribution from the membrane to the cell were accentuated (Fig. 5b). Four days after PLGF-1 injection, normal RPE tight junctions were observed, with only residual ZO-1 observed in the cytoplasm (Fig. 5c). Injection of VEGF-E did not induce any effect on RPE junction integrity (Fig. 5c). Interestingly, the increased RPE permeability induced by PLGF-1 was associated with the accumulation of sub-retinal fluid at $24 \mathrm{~h}$ (Fig. 5f).
Fig. 4 Effect of MEK1/2 inhibition (UO126) on PLGF-1-induced ERK1/2 phosphorylation and RPE cell permeability. a Levels of ERK1/2 and phosphorylated ERK1/2 (P-ERK1/2) at $10 \mathrm{~min}$ and $1 \mathrm{~h}$ after PLGF-1 stimulation, with or without pretreatment with UO126. Time course of TER (b) and inulin flux (c) after incubation with $1.0 \mathrm{nmol} / \mathrm{l}$ VEG165 (triangles, grey bars) or $2.0 \mathrm{nmol} / 1$ PLGF-1 (diamonds, black bars) with or without pretreatment with UO126 (grey squares, dotted bars: PLGF-1+UO126; black squares, lined bars: VEGF-165+UO126; control, open bars) $(n=3) . * p<0.05$, $* * p<0.01, * * * p<0.001$

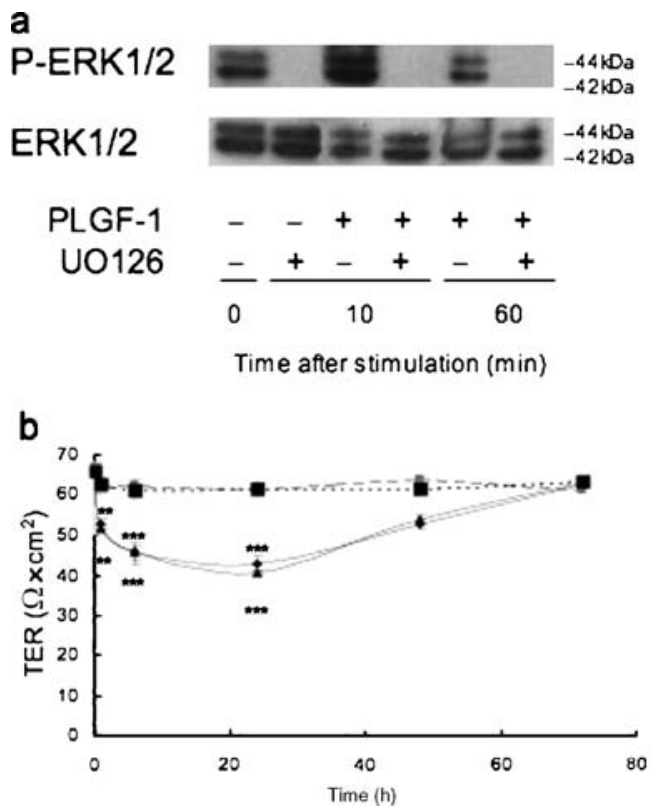

C

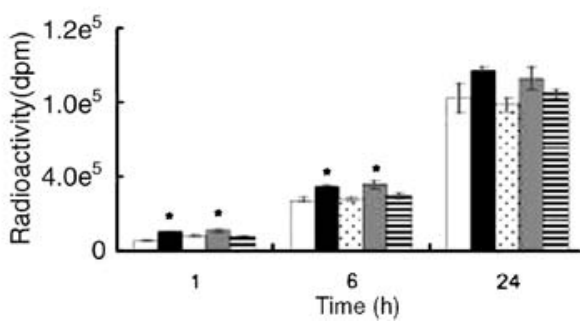




\section{a}
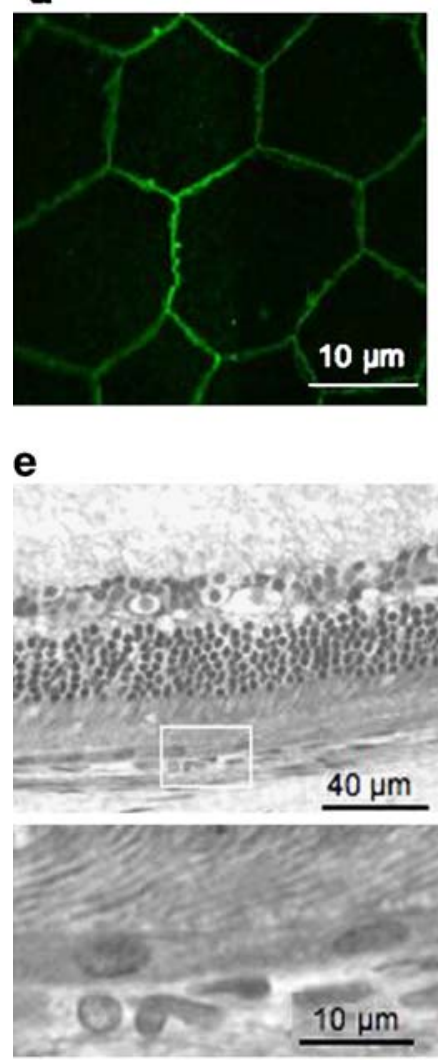

PBS $24 \mathrm{~h}$ b

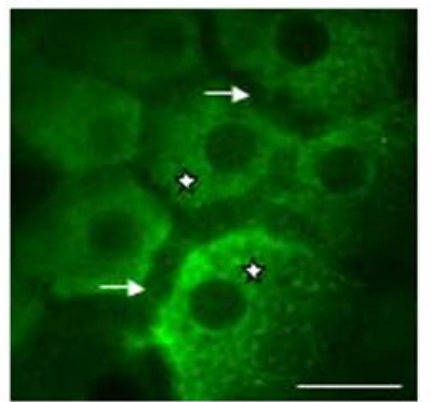

f
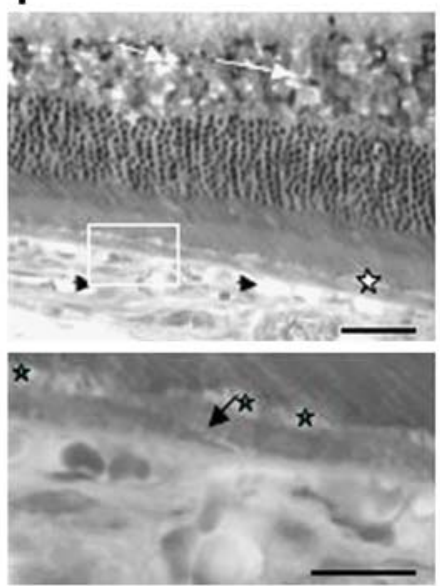

PLGF-1 $24 \mathrm{~h}$

Fig. 5 Reversible external haemato-retinal barrier breakdown in vivo induced via VEGFR-1 activation. a ZO-1 immunohistochemistry on whole flat-mounted RPE cells showing normal tight junctionassociated ZO-1, in PBS-injected rats. b $24 \mathrm{~h}$ after PLGF-1 injection, disruption of RPE tight junctions with intercellular spaces (white arrows) and intracellular ZO-1 distribution (white stars) is observed. c At 4 days after PLGF-1 injection, ZO-1 staining is mostly concentrated in the cell membranes (white arrows) with some staining of ZO-1 still in the cytoplasm (white stars). d VEGF-E does not alter

Measurement of retinal thickness showed that in eyes treated with PLGF-1, the retinal thickness was significantly increased $(344 \pm 20 \mu \mathrm{m})$ compared with PBS-injected eyes $(292 \pm 39.8)(p<0.01)$, suggesting that retinal oedema is caused by PLGF-1 injection in the vitreous cavity. PLGF-1 also induced vasodilatation of the choriocapillaries.

By day 4 after treatment, along with the restoration of RPE cell junction integrity, absorption of the sub-retinal fluid was seen (Fig. 5g). In eyes injected with PBS or VEGF-E no effect on the retina or choriocapillary structures and no sub-retinal fluid accumulation were observed (Fig. 5e,h).

PLGF-1 is present in the vitreous of patients with diabetic retinopathy Significant levels of PLGF (33 to $806 \mathrm{pg} / \mathrm{ml}$ )
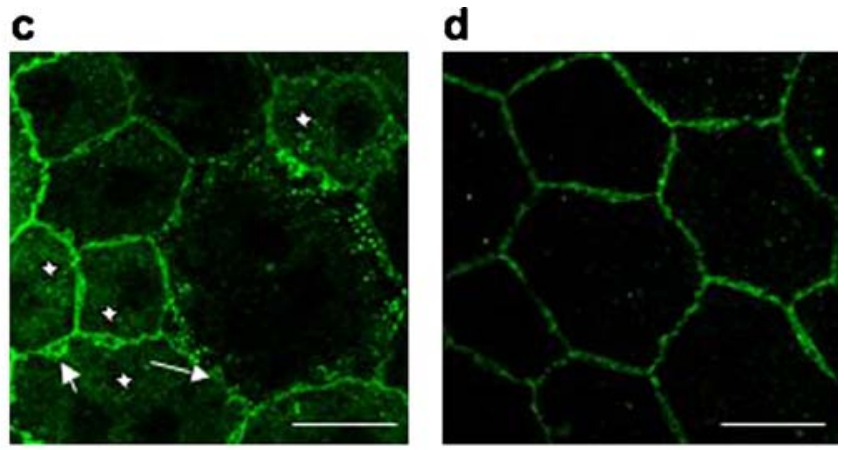

g

h
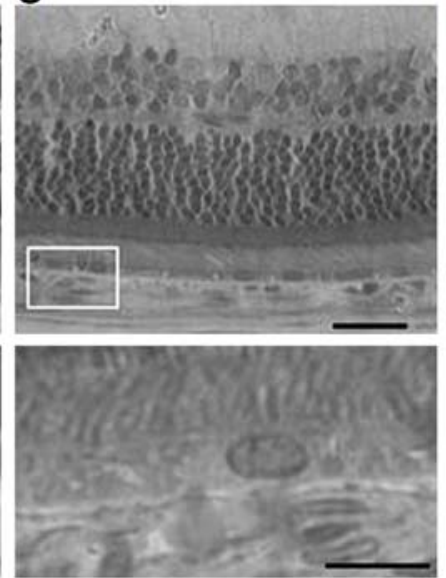

PLGF-1 4 days
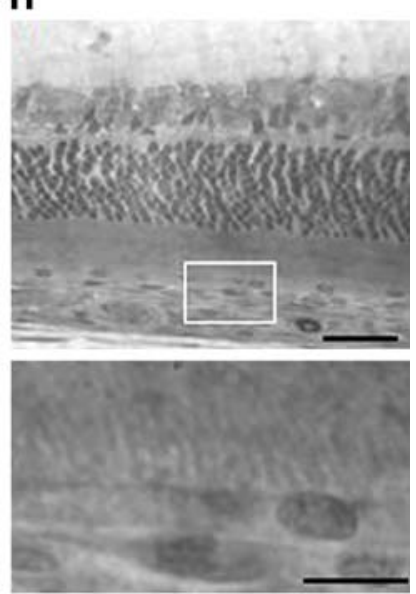

VEGF-E $24 \mathrm{~h}$

ZO-1 distribution at $24 \mathrm{~h}$. Bar=10 $\mu \mathrm{m}$. e Semi-thin sections at low (upper panel, bar $=40 \mu \mathrm{m}$ ) and high (lower panel, bar=10 $\mu \mathrm{m}$ ) magnification, showing normal structure of the retina and RPE cells $24 \mathrm{~h}$ after PBS injection. f Disruption of RPE tight junctions (black arrows), sub-retinal fluid accumulation (stars), retinal oedema (white arrows) and dilatation of the choriocapillaries (arrowheads) were detected $24 \mathrm{~h}$ after PLGF-1 injection. g Recovery of the normal retinal structure 4 days after the PLGF-1 injection. h Undisturbed retinal structure at $24 \mathrm{~h}$ after injection of VEGF-E

were found in the vitreous of all seven patients with diabetic retinopathy. In the vitreous of the six matched control subjects, PLGF levels were below detectable levels. Interestingly, the highest vitreous levels of PLGF-1 were associated with more severe expression of clinical diabetic retinopathy in these patients (Table 1 ).

\section{Discussion}

Macular oedema is one of the leading causes of poor visual acuity in patients with diabetic retinopathy [14]. VEGF plays an important role in the pathogenesis of diabetic retinopathy [21], inducing both pre-retinal neovascularisa- 
Table 1 Levels of PLGF-1 (pg/ml) in the vitreous of patients with diabetic retinopathy

\begin{tabular}{|c|c|c|}
\hline Patient & $\begin{array}{l}\text { PLGF levels } \\
(\mathrm{pg} / \mathrm{ml})\end{array}$ & Status of the retina \\
\hline 1 & 806.5 & Proliferative DR with macular oedema \\
\hline 2 & 75 & $\begin{array}{l}\text { Proliferative DR with tractional retinal } \\
\text { detachment }\end{array}$ \\
\hline 3 & 131 & $\begin{array}{l}\text { Proliferative DR with vitreous } \\
\text { haemorrhage }\end{array}$ \\
\hline 4 & 72 & $\begin{array}{l}\text { Proliferative DR with tractional retinal } \\
\text { detachment }\end{array}$ \\
\hline 5 & 33 & $\begin{array}{l}\text { Proliferative DR without macular } \\
\text { oedema }\end{array}$ \\
\hline 6 & 135 & Proliferative DR with macular oedema \\
\hline 7 & 500 & Proliferative DR with iris rubeosis \\
\hline
\end{tabular}

$D R$, diabetic retinopathy

tion and disruption of the blood-retinal barrier. In endothelial cells and in experimental retinopathy, VEGF induces both increased transcellular pathways via vesicles [22] and paracellular transport through phosphorylation of junction proteins [23]. Anti-VEGF strategies under evaluation tend to show that blocking VEGF decreases vessel leakage and may decrease retinal oedema [24]. Exploration of macular oedema by optical coherence tomography reveals that the incidence of serous macular detachment, mostly suggestive of RPE cell junction dysfunction, is higher than previously assessed [25-27]. While extensive work has been carried out to identify factors influencing the blood-retinal barrier, the mechanisms implicated in the RPE barrier regulation have been poorly explored.

The data obtained in our present study demonstrate that specific activation of VEGFR-1, VEGF165 and PLGF-1 in response to hypoxia or insulin disturbs the external bloodretinal barrier in vitro and in vivo, contributing to fluid accumulation under the retina and in the retinal layers. Using specific VEGF receptor agonists and inhibition of VEGFR-1 or VEGFR-2 production by specific antisense oligonucleotides, we found that the VEGF-induced external blood-retinal barrier permeability is mediated through VEGFR-1 and not through VEGFR-2. Takahashi et al. [28] reported that Trimeresurus flavoviridis snake venom VEGF induces vascular permeability through VEGFR-1 signalling pathways. In Vegf- $a$ transgenic mice, increased angiogenesis and oedema develop, while in transgenic mice overexpressing only Vegfr-2, angiogenesis without increased vessel permeability was observed [29]. Novel pharmacological strategies aim at inhibiting VEGF receptors, rather than blocking VEGF itself [30]. However, only the VEGFR-1, but not the VEGFR-2 promoter contains hypoxia-inducible factor 1 alpha binding sequence, a finding which could be directly involved in the observed hypoxia-induced upregulation of VEGF [31].
Our experiments show unequivocally that VEGF-induced RPE permeability is specifically mediated through VEGFR-1. Our in vitro findings demonstrate that the production of PLGF-1 and VEGFR-1 is upregulated under hypoxic conditions, subsequently inducing alteration of the RPE barrier function. Interestingly, not only hypoxia but also insulin directly induced a transitory upregulation of PLGF-1 associated with an increased permeability of RPE cells in vitro. It has been reported that PLGF-1 plays a role in the pathogenesis of diabetic retinopathy through increased levels of VEGF and activation of protein kinase B, c-Jun $\psi$-terminal kinase, hypoxia-inducible factor 1 alpha, nuclear factor $\mathrm{\kappa B}$ and activator protein 1 in the retina [19].

Using specific MEK1/2 inhibitors, we found that, in RPE cells, VEGFR-1 activation by PLGF-1 and subsequent increased cell permeability involves the MEK/ERK signalling pathway.

An acute increase of PLGF-1 concentration within the vitreous of rat eyes induced alterations of the cell-cell junction complex with cytoplasmic translocation of tight junction proteins and increased intercellular spaces. These RPE cell tight junction modifications were associated with sub-retinal fluid accumulation and increased retinal thickness and oedema. Interestingly, an ultrastructural breakdown of the RPE barrier has also been observed in 5-month streptozotocin-induced diabetic rats [32].

The important potential role of PLGF-1 in the pathogenesis of diabetic retinopathy is in line with additional clinical observations in pregnancy and diabetes. Patients with diabetic retinopathy have high levels of vitreous PLGF-1 with an apparent development of more severe diabetic retinopathy detected in the eyes with higher levels.

The in vitro and in vivo observations derived from our present study show that PLGF-1 plays a crucial role in the induction of RPE-blood barrier disruption, an important aspect of diabetic retinopathy.

In summary, we have demonstrated that through the acute activation of VEGFR-1 and ERK1/2 pathway, PLGF-1 regulates the external blood-retinal barrier function by a direct effect on RPE cell tight junctions.

In therapeutic terms, neutralisation of VEGF in the retina could be harmful, possibly increasing retinal ischaemia. Therefore, specific regulation of PLGF-1 (or VEGFR-1) may be a logical alternative. This possible mode of treatment for retinal and macular oedema associated with diabetic retinopathy is now under evaluation.

Acknowledgements This work was funded by EU Craft project no. QLK6-CT-2002-71548 and INSERM fund Avenir Project. We also acknowledge the foundation Dalloz Fondation de France for supporting this work.

Duality of interest The authors have no duality of interest or commercial interests in any of the reagents used. 


\section{References}

1. Caldwell RB, Bartoli M, Behzadian MA et al (2003) Vascular endothelial growth factor and diabetic retinopathy: pathophysiological mechanisms and treatment perspectives. Diabetes/Metab Res Rev 19:442-455

2. Butler JM, Guthrie SM, Koc M et al (2005) SDF-1 is both necessary and sufficient to promote proliferative retinopathy. J Clin Invest 115:86-93

3. Meleth AD, Agron E, Chan CC et al (2005) Serum inflammatory markers in diabetic retinopathy. Invest Ophthalmol Vis Sci 46:4295-4301

4. Grant MB, Afzal A, Spoerri P, Pan H, Shaw LC, Mames RN (2004) The role of growth factors in the pathogenesis of diabetic retinopathy. Expert Opin Investig Drugs 13:1275-1293

5. Antonetti DA, Barber AJ, Khin S, Lieth E, Tarbell JM, Gardner TW (1998) Vascular permeability in experimental diabetes is associated with reduced endothelial occludin content: vascular endothelial growth factor decreases occludin in retinal endothelial cells. Diabetes 47:1953-1959

6. Hofman P, Blaauwgeers HG, Tolentino MJ et al (2000) VEGF-A induced hyperpermeability of blood-retinal barrier endothelium in vivo is predominantly associated with pinocytotic vesicular transport and not with formation of fenestrations. Vascular endothelial growth factor-A. Curr Eye Res 21:637-645

7. Campochiaro PA (2000) Retinal and choroidal neovascularization. J Cell Physiol 184:301-310

8. Van Nieuw Amerongen GP, van Hinsbergh VW (2002) Targets for pharmacological intervention of endothelial hyperpermeability and barrier function. Vascul Pharmacol 39:257-272

9. Ohno-Matsui K, Yoshida T, Uetama T, Mochizuki M, Morita I (2003) Vascular endothelial growth factor upregulates pigment epithelium-derived factor expression via VEGFR-1 in human retinal pigment epithelial cells. Biochem Biophys Res Commun 303:962-967

10. Khaliq A, Foreman D, Ahmed A et al (1998) Increased expression of placenta growth factor in proliferative diabetic retinopathy. Lab Invest 78:109-116

11. Christinger HW, Fuh G, de Vos AM, Wiesmann C (2004) The crystal structure of placental growth factor in complex with domain 2 of vascular endothelial growth factor receptor-1. J Biol Chem 279:10382-10388

12. Autiero M, Luttun A, Tjwa M, Carmeliet P (2003) Placental growth factor and its receptor, vascular endothelial growth factor receptor-1: novel targets for stimulation of ischemic tissue revascularization and inhibition of angiogenic and inflammatory disorders. J Thromb Haemost 7:1356-1370

13. Tjwa M, Luttun A, Autiero M, Carmeliet P (2003) VEGF and PlGF: two pleiotropic growth factors with disctinct roles in development and homeostasis. Cell Tissue Res 314:5-14

14. Lightman S, Towler HM (2003) Diabetic retinopathy. Clin Cornerstone 5:12-21

15. Dunn KC, Aotaki-Keen AE, Putkey FR, Hjelmeland LM (1996) ARPE-19, a human retinal pigment epithelial cell line with differentiated properties. Exp Eye Res 62:155-169

16. Piret JP, Mottet D, Raes M, Michiels C (2002) $\mathrm{CoCl}_{2}$, a chemical inducer of hypoxia-inducible factor-1, and hypoxia reduce apoptotic cell death in hepatoma cell line HepG2. Ann N Y Acad Sci 973:443-447
17. Rakic JM, Lambert V, Devy L et al (2003) Placental growth factor, a member of the VEGF family, contributes to the development of choroidal neovascularization. Invest Ophthalmol Vis Sci 44:3186-3193

18. Masood R, Cai J, Zheng T, Smith DL, Naidu Y, Gill PS (1997) Vascular endothelial growth factor/vascular permeability factor is an autocrine growth factor for AIDS-Kaposi sarcoma. Proc Natl Acad Sci U S A 94:979-984

19. Poulaki V, Joussen AM, Mitsiades N, Mitsiades CS, Iliaki EF, Adamis AP (2004) Insulin-like growth factor-I plays a pathogenetic role in diabetic retinopathy. Am J Pathol 165:457-469

20. Fan F, Wey JS, McCarty MF et al (2005) Expression and function of vascular endothelial growth factor receptor-1 on human colorectal cancer cells. Oncogene 24:2647-2653

21. Witmer AN, Vrensen GF, van Noorden CJ, Schlingemann RO (2003) Vascular endothelial growth factors and angiogenesis in eye disease. Prog Retin Eye Res 22:1-29

22. Fu BM, Shen S (2003) Structural mechanisms of acute VEGF effect on microvessel permeability. Am J Physiol Heart Circ Physiol 284:H2124-H2135

23. Antonetti DA, Barber AJ, Hollinger LA, Wolpert EB, Gardner TW (1999) Vascular endothelial growth factor induces rapid phosphorylation of tight junction proteins occludin and zonula occludens 1. A potential mechanism for vascular permeability in diabetic retinopathy and tumors. J Biol Chem 274:2346323467

24. Cunningham ETJ, Adamis AP, Altaweel M et al (2005) A phase II randomized double-masked trial of pegaptanib, an anti-vascular endothelial growth factor aptamer, for diabetic macular edema. Ophthalmology 112:1747-1757

25. Markomichelakis NN, Halkiadakis I, Pantelia E et al (2004) Patterns of macular edema in patients with uveitis: qualitative and quantitative assessment using optical coherence tomography. Opthalmology 111:946-953

26. Ozdemir H, Karacorlu M, Karacorlu S (2005) Serous macular detachment in diabetic cystoid macular oedema. Acta Ophthalmol Scand 83:63-66

27. Otani T, Kishi S, Maruyama Y (1999) Patterns of diabetic macular edema with optical coherence tomography. Am J Ophthalmol 127:688-693

28. Takahashi H, Hattori S, Iwamatsu A, Takizawa H, Shibuya M (2004) A novel snake venom vascular endothelial growth factor (VEGF) predominantly induces vascular permeability through preferential signaling via VEGF receptor-1. J Biol Chem 279:46304-46314

29. Kiba A, Sagara H, Hara T, Shibuya M (2003) VEGFR-2-specific ligand VEGF-E induces non-edematous hyper-vascularization in mice. Biochem Biophys Res Commun 301:371-377

30. Patel N, Sun L, Moshinsky D et al (2003) A selective and oral small molecule inhibitor of vascular epithelial growth factor receptor (VEGFR)-2 and VEGFR-1 inhibits neovascularization and vascular permeability. J Pharmacol Exp Ther 306:838-845

31. Gerber HP, Condorelli F, Park J, Ferrara N (1997) Differential transcriptional regulation of the two vascular endothelial growth factor receptor genes. Flt-1, but not Flk-1/KDR, is up-regulated by hypoxia. J Biol Chem 272:23659-23667

32. Bensaoula T, Ottlecz A (2001) Biochemical and ultrastructural studies in the neural retina and retinal pigment epithelium of STZdiabetic rats: effect of captopril. J Ocular Pharmacol Ther 17:573586 